\title{
Title: Academics' perceptions of students' motivation for learning and their own motivation for teaching in a marketized higher education context
}

Short title: Motivation in student 'consumers'

\begin{abstract}
Naomi King ${ }^{1 a^{*}}$ and Louise Bunce ${ }^{1 a}$
1 Department of Psychology, University of Winchester, King Alfred Campus, Sparkford Road, Winchester, SO22 4NR, UK

a Present address: Naomi King and Louise Bunce have moved since this study was undertaken and are now based at the Department of Sport, Health Sciences and Social Work, Faculty of Health and Life Sciences, Oxford Brookes University, Jack Straw's Lane, Oxford, OX3 OFL, UK

* Correspondence should be addressed to: Naomi King, MRG 47a, Department of Sport, Health Sciences and Social Work, Faculty of Health and Life Sciences, Oxford Brookes University, Jack Straw's Lane, Oxford, OX3 0FL, UK (email: nking@brookes.ac.uk)
\end{abstract}

\section{Keywords:}

student 'consumer'; self-determination theory; intrinsic motivation; approaches to learning; higher education; thematic analysis

\section{Acknowledgements:}

We would like to express our thanks to the academics who gave up their time to participate in our study.

Data availability statement:

Data for this study cannot be made available as it would compromise the confidentiality and informed consent of participants. 


\title{
Academics' perceptions of students' motivation for learning and their own motivation for teaching in a marketized higher education context
}

\begin{abstract}
Background

The marketisation of higher education (HE), which positions students as consumers and academics as service providers, may adversely affect students' motivation for learning and academics' motivation for teaching. According to self-determination theory (SDT), highquality forms of motivation are achieved when individuals experience fulfilment of three psychological needs: competence, autonomy, and relatedness.
\end{abstract}

\section{Aims}

This study applied SDT to examine academics' perceptions of whether the marketized HE context in England, UK, supported or undermined these three psychological needs for their students and for themselves. It also examined their perceptions of the impact that this context had on their teaching.

\section{Sample}

Participants were 10 academics teaching at five post-1992 higher education institutions in England, UK.

\section{Method}

Semi-structured interviews were conducted and subsequently analyzed using thematic analysis.

Results

Academics observed that students identifying as consumers seemed to display lower levels of 
competence, autonomy, and relatedness. This contributed to an HE environment that diminished the academics' own psychological needs. Although some felt able to improve student motivation through their teaching, others felt demotivated and disempowered by topdown pressure from managers and bottom-up pressure from students.

\section{Conclusions}

The marketized HE context may undermine high-quality motivation for students' learning and academics' teaching. Academics should be supported to teach in ways that facilitate competence, autonomy, and relatedness in their students and themselves. 


\section{Introduction}

Students who are intrinsically motivated to learn, or have internalized extrinsic goals such as gaining good grades, demonstrate higher levels of satisfaction with their education, better psychological wellbeing, and higher academic achievement (Deci, Vallerand, Pelletier, \& Ryan, 1991; Niemiec \& Ryan, 2009; Ryan \& Deci, 2000, 2002). Learning environments play a crucial role in influencing students' experience of motivation (for reviews, see Deci et al., 1991; Niemiec \& Ryan, 2009). Educators can promote or inhibit the development of positive forms of motivation among their students through the ways in which they structure the learning environment, for example by using choice-driven or controlling styles of teaching (Deci et al., 1991; Entwistle, McCune, \& Walker, 2001; Niemiec \& Ryan, 2009). Recent research also suggests that student motivation for learning in higher education (HE) is being influenced by broader socio-political contexts that operate beyond the educators' control: a marketized environment in which students have come to be defined as 'consumers' by some governments, policymakers, higher education institutions (HEIs), and even students themselves. Students who identify as consumers appear to be motivated not by an intrinsic interest in their subjects, but primarily by the extrinsic goal of gaining a degree which they perceive to be necessary for improving their future employment prospects (e.g., Bunce, Baird, \& Jones, 2017; Bunce \& Bennett, 2019; Haywood, Jenkins, \& Molesworth, 2011; Jabbar, Analoui, Kong, \& Mirza, 2018; Nixon, Scullion, \& Molesworth, 2011; Rolfe, 2002; Tomlinson, 2014, 2017; Wong \& Chiu, 2019). This is problematic, because much evidence has shown that extrinsically motivated students demonstrate lower satisfaction, psychological wellbeing, and academic achievement, as well as a range of diminished transferable skills including lower engagement, persistence, creativity, flexible thinking, and personal growth (Deci et al., 1991; Niemiec \& Ryan, 2009; Ryan \& Deci, 2000, 2002).

Educators who are intrinsically motivated in their teaching are more likely to facilitate 
intrinsic motivation in their students (Pelletier, Séguin-Lévesque, \& Legault, 2002). However, pedagogic relations are bi-directional, and the attitudes and behaviours that students bring to the learning environment can promote or inhibit positive forms of motivation in their educators, and affect their teaching styles (Deci et al., 1991; Pelletier et al., 2002). In addition, educators' motivation may be affected by factors such as managerial pressure to follow imposed curricula and attain performance targets (Deci et al., 1991; Niemiec \& Ryan, 2009; Pelletier et al., 2002). While academics could play a significant role in transforming the attitudes and behaviours of student 'consumers', no research to date has applied a theoretical framework to gain psychological insight into academics' perceptions of the effect of the marketized HE learning environment on students' motivation, their own motivation, and their own teaching styles. The current study addresses this gap by using selfdetermination theory (SDT) to analyze interview data collected from academics teaching in England, UK.

Higher education in England has undergone an ideological shift since tuition fees were introduced in 1998, along with other countries around the world including the United States, Canada, and Australia. As state funding has been cut and students have become more or wholly responsible for their tuition costs, HEIs have adopted policies of marketization and operate under stricter business models that tend towards conceptualizing students as consumers and academics as service providers (Komljenovik, Ashwin, McArthur, \& Rosewell, 2018; Naidoo, Shankar, \& Veer, 2011; Nixon et al., 2011; Tomlinson, 2014, 2017; Wong \& Chiu, 2019). Governments and policy advisors believe that this allows HEIs to benefit from competitive market pressure, and enables students to receive higher-quality teaching and resources (Department for Business, Innovation, and Skills, 2011, 2016; Naidoo et al., 2011). Consequently, among HEIs there is an increasing audit culture and a focus on achieving high student 'satisfaction' scores on performance metrics, such as the National 
Student Survey (NSS), UK, and the Teaching Excellence Framework (TEF), England (Komljenovik et al., 2018; Moran \& Powell, 2018). Many UK HEIs use intense consumerorientated marketing campaigns to recruit and retain students (Chapleo, 2010; Gokcen, 2014; Haywood et al., 2011), and often encourage their students to act as consumers by giving regular feedback and requesting improvement to services (Williams, 2011).

Empirical research, however, has found the marketization of HE to have detrimental effects on both students and academics. Students who see themselves as consumers tend to hold a sense of academic entitlement, adopt a surface approach rather than a deep approach to learning, and regard education as a commodity (e.g., Bunce et al., 2017; Bunce \& Bennett, 2019; Haywood et al., 2011; Jabbar et al., 2018; Nixon et al., 2011; Rolfe, 2002; Tomlinson, 2014, 2017; Wong \& Chiu, 2019). These attitudes and behaviours appear to be linked to extrinsic motivation for learning, with the end goal of getting a degree prioritized over ongoing self-development and a genuine learning experience. Interviews and focus groups with 68 undergraduate students studying at seven HEIs in the United Kingdom revealed that those who identified strongly as consumers often adopted instrumentalist approaches to learning, and tried to calculate the 'value' of their HE experiences in financial terms (Tomlinson, 2014, 2017). They saw themselves as paying for good 'service' that would lead to a good degree and graduate employment, and appeared to view lectures as a passive form of entertainment (Tomlinson, 2014). Students who did not identify as consumers reported that many of their peers seemed passive and apathetic towards their learning, while still expecting to get good grades that would be seen favourably by employers (Tomlinson, 2014, 2017).

Similar findings were reported by Haywood and colleagues (2011), who interviewed 60 students from one HEI in England and focused on the stories they told about their learning experiences and dreams for the future. Many appeared to embrace a consumer ethic, describing how they avoided 'boring' and challenging parts of their courses that they 
considered irrelevant to their careers, and took little responsibility for their own learning (Haywood et al., 2011, p. 190). Another study based on interviews with 60 students from one HEI in England found that many tended to opt for the easiest and most 'fun' routes to 'get a 2:1 [...] without sort of having to really work as hard' (Nixon et al., 2011, pp. 204, 202). They often spoke about extrinsic goals and appeared to engage in consumerist thinking, summed up in one student's statement that his aim was 'partly learning, but mostly to get a job $[\ldots]$ that gets you money, and then a wife, and house and children...' (Nixon et al., 2011, p. 201).

The relation between a student 'consumer' identity and quality of motivation, as assessed by approaches to learning, was quantified in a survey of 587 students in England (Bunce \& Bennett, 2019). A surface approach to learning involves using passive or rote-learning techniques with the extrinsic goal of receiving a pass with minimal effort, whereas a deep approach involves synthesizing, evaluating, and making meaning, with the intrinsic goal of achieving understanding (Marton \& Säljö, 1976). Bunce and Bennett (2019) found that students who identified more strongly as consumers were less likely to take a deep approach and more likely to take a surface approach to learning, which consequently had a negative impact on their academic performance.

A small body of work has begun to explore the perspectives of academics in England on the marketization of HE, and revealed how they also perceived student 'consumers' to have extrinsic motivation for learning. This had negative effects on the academics' own motivation for teaching, and on their teaching styles. In a study examining the views of 70 academics at four HEIs on the impact of introducing tuition fees, some reported how they were 'expected to deliver a different style of teaching, geared to "training" students to achieve the highest possible marks' (Rolfe, 2002, p. 173). Many expressed disappointment about their students' low interest and engagement, which in turn made them feel devalued and less satisfied with 
their teaching. Similarly, Wong and Chiu (2019) described how some academics from a sample of 30 at two HEIs felt that they needed to 'keep students entertained' in lectures, which sometimes caused internal conflict; as observed by one academic, 'Students want to learn less, therefore we teach them less? Is that how it works?' (Wong \& Chiu, 2019, p. 10). Such views were reflected again in a study of 22 business school academics at three HEIs, some of whom reported how they struggled to engage students who did not see the value of learning for its own sake (Jabbar et al., 2018). Many also spoke about top-down management pressure in the form of 'unmanageable workloads and time pressures' and the need to gain high student satisfaction scores on the NSS (Jabbar et al., 2018, p. 95). This contributed to 'a culture of academic stress', which left them feeling 'pressured, demoralised and demotivated' (Jabbar et al., 2018, p. 95). Increasingly stressful conditions for academics were highlighted in a report by the UK's Higher Education Policy Institute (HEPI), which described an escalation of poor mental health among academics due to factors including excessive workloads, metrics-driven performance management policies, and a culture of workplace surveillance (Morrish, 2019).

Together, this research suggests that the marketized HE context undermines intrinsic motivation for both students and academics. If students identify as consumers, they appear to experience extrinsic motivation for learning and a range of negative outcomes that will not serve them well in employment (e.g., lower academic achievement, lack of transferable skills). If academics encounter pressure from students and managers to 'satisfy' their students in superficial ways, they appear to experience a range of negative outcomes that inhibit their intrinsic motivation for teaching (e.g., anxiety, frustration, disillusionment with their work). This means that academics may be less likely to foster students' intrinsic motivation through their teaching styles, and students may be less likely to foster academics' intrinsic motivation through displaying enthusiasm for their subjects. 
While existing research has identified the problematic nature of extrinsic motivation in the marketized HE environment, no studies have yet focused on the specific socio-contextual factors that could facilitate or impede intrinsic motivation in students and academics. The current study addresses this gap using SDT. This well-established theory defines a continuum of different types of motivation that vary in the extent to which individuals internalize their goals (Deci et al., 1991; Ryan \& Deci, 2000, 2002). It would place the form of motivation exhibited by student 'consumers' on the lower-quality side of extrinsic motivation. Such motivation occurs when an individual feels controlled by external contingencies and performs activities for instrumental reasons, for example to attain a reward or avoid punishment ('external regulation') or to prevent guilt and anxiety or enhance self-esteem ('introjected regulation'). Higher-quality extrinsic motivation ensues when an individual accepts and values their instrumental goal ('identification') or assimilates it with their sense of self ('integrated regulation'). This motivation might be experienced by students if they see their course as relevant to a personal life goal, or by academics if they think that a new compulsory curriculum will actually help them to teach in better ways. These extrinsic forms of motivation differ from 'intrinsic motivation', which occurs when an individual engages with an activity for its own sake with a full sense of independence and volition (Deci et al., 1991; Ryan \& Deci, 2000, 2002).

Self-determination theory proposes that humans are innately predisposed towards intrinsic motivation and personal growth through fulfilment of three basic psychological needs: competence, autonomy, and relatedness (Deci et al., 1991; Ryan \& Deci, 2000, 2002). Satisfaction of these needs is dependent on social contexts, which can be either supportive or inhibitive. Competence is defined as understanding how to attain a desired outcome, and being efficacious in performing the required actions. Autonomy involves self-initiating and self-regulating one's own behaviour; it does not mean self-sufficiency or individualism, but 
that the locus of control is felt to be within the self. Relatedness involves developing secure and satisfying connections with supportive others (Deci et al., 1991; Ryan \& Deci, 2000, 2002). The extent to which a person feels that their three psychological needs are met affects the quality of their motivation.

Although an extensive amount of research has applied SDT to analyze students' motivation in general, especially in school environments, this theory has not been used to analyze students' motivation for learning or academics' motivation for teaching in a marketized HE context. The first aim of the current study was to examine academics' perceptions of the extent to which this HE context appeared to support or undermine their students' three basic psychological needs. The second aim was to examine academics' perceptions of the extent to which it supported or undermined their own psychological needs, and the impact that it had on their endeavours to teach in ways that cultivated high-quality motivation in their students. Interviews with 10 academics at five post-1992 HEIs in England were conducted to explore these issues, and the data were analyzed using a hybrid (inductive and deductive) form of thematic analysis.

\section{Method}

\section{Participants}

A purposive sample of 10 academics (four female and six male) was recruited from five post-1992 universities in England. Eight academics were senior lecturers, one was a principal lecturer, and one was a teaching fellow. They had an average of 12.9 years of HE teaching experience $(S D=10.17$, range 3-35 years), and taught in one or more of the following disciplines: analytics, biosciences, biomedical sciences, business, computing, economics, education, estate management, health studies, planning, psychology, sport and exercise science, and urban design. For further participant details, see Table 1. To maintain 
anonymity, the institutional membership and subjects taught by individual participants are not disclosed. All names have been replaced by participant numbers.

Table 1

Participant Demographics

\begin{tabular}{|c|c|c|c|}
\hline Participant number & Gender & Age (years) & $\begin{array}{c}\text { Higher education } \\
\text { teaching experience } \\
\text { (years) }\end{array}$ \\
\hline 1 & Male & $60-69$ & $35-39$ \\
\hline 2 & Male & $50-59$ & $5-9$ \\
\hline 3 & Female & $50-59$ & $5-9$ \\
\hline 4 & Male & $40-49$ & $5-9$ \\
\hline 5 & Female & $30-39$ & $5-9$ \\
\hline 6 & Male & $50-59$ & $20-24$ \\
\hline 7 & Male & $30-39$ & $5-9$ \\
\hline 8 & Female & $40-49$ & $<5$ \\
\hline 9 & Female & $40-49$ & $20-24$ \\
\hline 10 & Male & $60-69$ & $10-14$ \\
\hline
\end{tabular}

\section{Procedure}

Participants responded to email invitations sent to departments of post-1992 universities across England. These invited academics to take part in a study about teaching and learning in the current HE context in which students are responsible for their tuition fees. Individual, semi-structured interviews were conducted face-to-face or over the telephone by the first author. Interviews lasted approximately 30-60 min. Participants were asked a series of 
questions, created collaboratively by both authors in accordance with Wengraf's (2001) criteria for openness and non-leading neutrality. The questions were designed to encourage participants to talk at length and in depth about their experiences (Galletta, 2013). They ranged from relatively broad (e.g., 'Could you tell me about today's students' attitudes and behaviours towards their learning?') to more specific and grounded in elements of SDT (e.g., 'What do you think motivates today's students to come to university?').

In line with Wengraf's (2001) and Galletta's (2013) suggestions for optimal semistructured interviewing, the interviewer used a number of follow-up questions and prompts to encourage participants to elaborate on their initial responses. Participants were also asked to give concrete examples to support their statements, ensuring that their perceptions and interpretations of students' experiences were based on real-world evidence (e.g., interactions with and observations of their students). In addition, participants were asked to indicate the approximate proportions of students to which their statements applied if they did not mention this of their own accord. Interviews were transcribed verbatim.

\section{Analysis}

Transcripts were analyzed using thematic analysis (TA), a well-established method for identifying, analyzing, and reporting patterns within qualitative data (Braun \& Clarke, 2006, 2012). Unlike other methods which are bound to particular theories and epistemological positions, TA is theoretically flexible and can be used in an inductive (data-driven) or deductive (theory-driven) way. The current study used a hybrid approach (Fereday \& MuirCochrane, 2006; see also Braun \& Clarke, 2006, 2012; Nowell, Norris, White, \& Moules, 2017), whereby the initial codes were drawn primarily from the raw data but a framework based on SDT was used for the integration of codes and development of themes.

TA involves a six-phase process, which the authors followed rigorously to ensure that the analysis was conducted in a consistent manner and the findings could be judged as credible. 
An audit trail was kept in the form of all raw data, annotated transcripts, tables, diagrams, memos, and an extensive body of notes which documented comprehensively how the analysis evolved (Nowell et al., 2017; Wolf, 2003). In line with guidelines for maintaining trustworthiness in TA (Nowell et al., 2017), the authors routinely conducted segments of independent analysis before reviewing and discussing the outcomes. All decisions were recorded, and the authors engaged in ongoing, reflexive dialogue throughout the analytic procedure (Braun \& Clarke, 2006, 2012).

The initial familiarization phase involved listening to each of the audio-recordings while making notes, then proceeding with reading, re-reading, and annotating all of the transcripts. The data were then coded inductively with a mixture of 'semantic codes', which summarized surface meanings grounded in the data (e.g., 'Many students are seen as demanding excessive support'), and 'latent codes', which drew out the deeper and more conceptual meanings (e.g., 'Some students appear to need "spoon-feeding" - a detrimental image of infantilization and literal consumption of education') (Braun \& Clarke, 2006, 2012). Following discussion between both authors to determine the accuracy of all codes, these were collated into an expansive list alongside relevant data extracts.

The analysis then shifted to a broader focus, constructing coherent and meaningful patterns (themes and subthemes) from the codes. The authors switched to a primarily deductive approach for this phase, reiteratively examining all coded data through the lens of SDT. Consistent application of this approach across the whole dataset (Nowell et al., 2017) generated three themes: 'competence', 'autonomy', and 'relatedness'. Within each of these themes, two contrasting subthemes emerged: 'fulfilment' and 'lack of fulfilment' of each of the three basic psychological needs. Each theme and subtheme provided a strong organizing concept for distinct clusters of codes, and together they fitted 'like pieces of a jigsaw puzzle' to offer a 'meaningful and lucid picture' of the overall dataset (Braun \& Clarke, 2012, p. 65). 
The themes and subthemes were carefully reviewed and revised, and checked to ensure that they had 'internal homogeneity' (meaningful data cohesion within the themes) and 'external heterogeneity' (clear differences between the themes) (Patton, 1990). Lastly, the authors conducted a reread of the entire dataset to ensure that the selected themes and subthemes captured the most important and relevant elements of the data in relation to the research question (Braun \& Clarke, 2006, 2012).

\section{Results and Discussion}

In this section, we first present academics' views on the extent to which their students appeared to experience fulfilment of their needs for competence, autonomy, and relatedness. Within each theme, we also present academics' own experiences of fulfilment of their basic psychological needs, and the ways in which this was felt to influence their teaching.

\section{Competence}

\section{Fulfilment of the need for competence}

Three academics (P8-P10) regarded the majority of their students as experiencing high levels of competence. Competence in this sense was perceived to be something that could be achieved by all students willing to put the necessary energy into learning, as opposed to an individual trait (e.g., intelligence quotient):

I view all learners $[\ldots]$ as competent. [...] They are making the learning, I'm not making the learning for them. [...] It's inviting them out on the dance floor. [Laugh] Because we can't dance the dance of making meaning unless you come on the dance floor. (P8) 
The academics attributed high competence partly to their students' desire to gain mastery of their subjects, but also to their own teaching styles that inspired students to participate, stimulated high levels of engagement, and empowered them to exceed their own expectations:

What I've done [with my innovative teaching style], or [...] we're trying to do a lot here $[\ldots]$ is $[\ldots]$ you can do stunningly well if you try, if you engage with what we're doing. [...] The students are surprising themselves, and demonstrating amazing levels of achievement. (P10)

Two of these academics explained how they played a central role in making students realize their own innate desire to engage in high-quality learning. They saw their main educator responsibility as 'teaching them how to learn to learn' (P10) and enabling them to make 'the overriding transition [to] being [...] in charge of their own learning' (P8). Participant 10 also described how he often needed to overcome students' initial preconceptions of HE learning, which were linked to consumer attitudes:

Their story was very much along the lines, "Well when we first started, you know, well we were thinking about value for money". [...] They now see that university's not something you buy. [...] They're learning how to be... "We've discovered that we're much better than we thought we were", because we are encouraging them to develop their sort of self-confidence. [...] It clearly has changed the way that some of them actually look at... what university's all about. (P10)

All three academics spoke about how they helped students to acquire a range of valuable transferable skills such as effective communication and critical thinking, as well as high achievement in terms of grades. Two described how their students seemed to undergo significant transformations in competence over the course of their degrees: 
I think, especially if you look at how they started and at the end, how the skills and the knowledge... [...] I think they get more and more competent. [...] You see a transformation in them from second to third year. [...] They do have the opportunity to $[\ldots]$ become much more critical in the way they think about the world. (P9)

We are concentrating very, very strongly on developing their soft skills of things like creativity, curiosity, communication, problem solving, and [...] storytelling. [...] They're learning how to communicate, [...] to develop their sort of self-confidence. [...] [Our recent graduates have] almost all 2:1s and firsts. (P10)

Seeing their students thrive in this way enhanced these three academics' own experiences of competence, enabling them to feel invigorated and confident in their teaching. They believed this to be a two-way process, in which both students and academics contributed to a vibrant learning environment that had reciprocal benefits.

\section{Lack of fulfilment of the need for competence}

Six academics (P1-P6) felt that the majority of their students experienced low levels of competence, which had decreased in recent years. This manifested in students showing a lack of confidence and perseverance, and poor understanding of how to achieve the grades and skills they desired. One further academic (P7) reported that his students appeared 'very variable' in their sense of competence, but that many struggled with their degrees. These academics described how such students seemed unable or unwilling to engage with their studies and produce work of a satisfying standard:

They struggle with the content, or they struggle to engage in the $[\ldots]$ subject matter. [...] It probably potentially challenges them, more than they would like it to. [...] Our students sometimes struggle with the theoretical side of things. (P7) 
These students were often perceived as reluctant to do preparatory work, take part in activities, or even attend lectures and seminars. According to the academics, they did not seem to fully grasp what HE learning involved:

I have a number of students that are very resistant to taking part. [...] Definitely any preparatory stuff, or if we have activities in classes, [low effort] manifests itself. [...] We are having problems with attendance. [...] I think some of our students [...] just don't understand what they don't know. So, they have no concept of where they are $[\ldots]$ or where they need to be. [...] The students that aren't putting the effort in $[\ldots]$ struggle to progress. (P5)

Such students appeared to want 'an easy ride' and expected academics to deliver 'not learning, not opportunities to learn, but [...] simply what is required for passing' (P2). The academics' felt that these students did not want to gain 'knowledge', but thought that they should be given 'information [...] something that doesn't really need to be extended upon, or digested' (P6). Instead of becoming critical thinkers and engaging in 'deep learning' (P6), the students seemed to rely largely on superficial learning techniques that focused primarily on memorization and regurgitation of teaching materials in assessments. This involved a passive, disengaged stance and poor comprehension of complex and challenging ideas (Entwistle et al., 2001; Marton \& Säljö, 1976). The students subsequently achieved lower grades, a pattern previously shown to be linked to a surface approach and consumer identity (Bunce \& Bennett, 2019).

Several academics associated these attitudes and behaviours explicitly with a consumer identity, reporting how students often expressed a sense of entitlement to good grades due to the fact that they were paying high tuition fees: 
I seem to get more comments about, "I pay your wages", "I'm paying for my degree", and we get a lot more disputes now, about what their grades are. [...] They don't see that it's actually down to what they have to contribute. [...] It's, 'I've paid for it, I want what I've paid for'. [...] They see it as, they're buying a product. (P3)

They did not blame the students for this approach, but believed that they had been encouraged to adopt these views by a discourse often promoted by politicians and policymakers, and sometimes by HEI marketing teams who displayed materials like 'posters all over the place saying, "Your fees equate to this"” (P5).

The academics perceived students with low competence as falling into two distinct categories. On one hand, they regarded some students as taking a hedonistic approach, treating university like a 'gap year' (P2), an 'amusement park' (P2), or an '18-30 holiday' (P4). In other words, having paid their fees, the academics observed these students as feeling that they deserved 'a VIP experience, a bit like a fast track to degrees' for very little effort (P2). On the other hand, another set of students appeared to experience greater stress and anxiety from paying high fees. They seemed to focus primarily on the extrinsic goal of getting a 2:1 or first class degree, which was linked to a fear of failure and unwillingness to take on academic challenges:

Part of it is a lack of willingness to take risk. [...] Intellectual discovery doesn't necessarily feature. [...] I think there's an anxiety to make mistakes. [...] [They've lost] the whole notion that it is actually $o k$ to a degree to learn from your mistakes [...] so everything needs to be prescribed. (P6)

They just sort of retreat away from the activity, [...] I think they're, you know, they're quite scared of these activities where they have to sort of look at the literature themselves. (P4) 
These two clusters of attitudes and behaviours reflect the student 'consumer' approaches reported in other UK studies, in which some students spoke about how they saw HE as something that should be easy, entertaining, and fun (Haywood et al., 2011; Nixon et al., 2011; Tomlinson, 2014, 2017), while others described experiencing a fear of failure and opting for the easiest routes of study (Nixon et al., 2011). Both of these outlooks revolved around low cognitive effort, and placed the extrinsic goal of acquiring a degree above that of in-depth learning and personal growth.

All academics in this subtheme explained in detail how they made substantial efforts to improve the experience of competence in their students. Most, however, thought that their own competence was hindered by limited control over their teaching. They felt that they could not challenge the students sufficiently for fear of recrimination, or because of objectives and restraints imposed by managers and government agency initiatives:

I do not think [students] are improving because there are so many controls that stop us from improving them. I would push my students far more if I didn't have the cost of the National Student Survey behind me the whole time. [...] But if the minute you start doing it, there's going to be complaints going in and you're going to be hauled before the head of department [...] you're not going to do that, you're not going to step out of line, so in the sense, we are encouraging mediocrity. (P1)

This reduced the academics' motivation and job satisfaction, an issue exacerbated for some by what they considered to be disproportionate workloads that led to potential or actual failure in meeting targets:

If you do everything that the university asks you to do on the teaching side $[\ldots]$ you'll fail as a researcher, you just won't have time. [...] In terms of workload plan, teaching 
is massively underrepresented. [...] There's an awful lot of [administrative] stuff, [...] all these additional activities that the university generates. (P4)

In some ways it's very stressful. [...] We are increasingly being given targets that I think are unrealistic $[\ldots]$ and more often than not, we are not meeting. [...] We, colleagues, you know, shrug and say, "Well... virus, you know. Doing our best”. (P2)

\section{Autonomy}

\section{Fulfilment of the need for autonomy}

Three academics (P8-P10) thought that the majority of their students experienced high levels of autonomy, becoming creative and flexible thinkers who acted of their own volition. They attributed this partly to the students' interest in their subjects, but also felt their teaching styles to be a significant factor. They gave students freedom and responsibility to pursue their own areas of interest, set their own goals, and use their initiative to tackle complex tasks:

I do teach questions, I do not teach answers. I teach the students how to research, how to do critical thinking and analysis, $[\ldots]$ so all of my assignments, from first year through to third year, are all based around broad topics, that they research to identify their [own] narrow topic. (P10)

These academics reported that they felt highly autonomous with their own teaching, and had strong support from their managers to implement and disseminate creative teaching styles:

I've always written my own modules, so [...] it's mine, I mean it's what I've created, and then I would change it according to how it plays out with that cohort of students. 
I definitely influence the teaching in the department. [...] We all have a little bit more... opportunities, and perhaps a new environment where we can learn from each other. (P9)

They acknowledged, however, that such 'freedom' (P10) was not universal across their HEIs, and described how some colleagues had to follow very specific module specification documents and pre-set teaching patterns.

\section{Lack of fulfilment of the need for autonomy}

Seven academics (P1-P7) felt that the majority of their students did not experience autonomy, and that this was something that had been lost over recent years. They explained how this manifested in students' reluctance to study of their own volition and go beyond attempting to follow direct instructions. These academics perceived many students as failing to realize that it was necessary to take the initiative, make their own decisions, and look for areas of personal interest to study:

I'd say, the majority of students now, don't see that they have to read, they don't see they have to learn. [...] I think they've lost [...] the fact that they should be studying themselves, and developing themselves, and reading around subjects. [...] A number of times I get a student write to me and say, "Can you not just give me the answers?" (P3)

They often linked this directly to a consumer approach:

They see themselves as paying for a degree. [...] They don't see the independent study side of things. [...] Quite a lot of students [are] not willing to do independent study, and not realizing that they need to study independently. (P5) 
These students were seen as demanding extensive and unreasonable support. Four academics used the metaphor of students wanting to be 'fed', evoking the image of them literally 'consuming' their education:

[They're] kind of very much, "Tell me the book I will use to pass my...", "Tell me how to write my answer...", "Tell me...", "Feed me...", very much, very demanding. (P2)

[It's] a bit [...] like coming to a restaurant, you don't expect that you're going to have help the chef out with preparing the course, I mean, it's all going to be delivered, ready, to your table, the only thing you have to do is fork it in your mouth. (P6)

This echoes the observations of Molesworth, Nixon, and Scullion (2009) that the marketization of HE encourages students to see their degrees as something that they are entitled to 'have', handed to them on a plate, rather than something that they need to gain through 'being' a learner. While this sense of consumer entitlement appeared to make students feel empowered in the short-term, it was regarded unanimously by the academics in this study as detrimental to long-term intellectual development and personal growth:

It's a strange irony really, by them paying more [...] we give them more, but actually $[\ldots]$ the outcome for them is less. (P4)

It also projected an infantilized image for the students (Williams, 2011), as the need for 'spoon-feeding' (P1, P5) and 'handholding' (P5, P7) suggested that they were unable to cope with adult responsibilities.

All of the academics in this subtheme explained how they tried to improve the autonomy of their students through a wide range of teaching methods that encouraged self-directed thinking, creativity, and choice. As in the 'competence' theme, however, most stated that they 
felt they had limited control over their teaching, and that their own autonomy had been diminished in recent years:

I don't feel I've got that much control in how I can... introduce new ideas to my learners. I feel I'm being [...] steered, forced, coerced [...] into designing my activities, my learning modules. [...] I don't feel I have the control of how I plan and design [compared to] [...] four, five years ago. (P2)

One of the implications of this model, the student-as-consumer, is [...] trust no longer seems to play a major role in the system. [...] [It] feels that we need to be directed in everything, $[\ldots]$ behaviour becomes kind of nearly algorithmic. That undermines $[\ldots]$ the sense of spontaneity and initiative. (P6)

They reported encountering pressure from managers, and experiencing various levels of frustration and stress over the ways in which their HEIs had become more focused on instrumentalist, corporate-like approaches that did not value academic freedom:

We obviously are target-driven. [...] We have inquests and enquiries into why $\mathrm{x}, \mathrm{y}$, and z module didn't go well. [...] It is very stressful. [...] We don't make any decisions without consulting with the $[\ldots]$ academic advice manager. [...] That is chipping away at my professionalism. (P2)

I think it's becoming increasingly mechanistic, and more and more time is actually being spent on checking what you're doing. [...] We've got to be checked on everything we do. [...] I feel the academic contribution is not $[\ldots]$ valued as it used to be. (P1)

Although the HEI management teams appeared to assume that such a 'business model' (P6) would increase efficiency and raise student satisfaction, the academics disagreed, arguing that 
the imposition of rigid assessment and accountability structures undermined their freedom to tailor their teaching for students in optimal ways. Such target-driven management, along with increasing levels of time-consuming bureaucracy and monitoring, was a key concern raised by the HEPI report (Morrish, 2019) and by many academics who participated in the UK's Times Higher Education Teaching Survey 2017 (Grove, 2017).

\section{Relatedness}

\section{Fulfilment of the need for relatedness}

Four academics (P7-P10) discussed how the majority of their students seemed to experience high levels of relatedness. In the learning context, this manifested in 'good rapport' (P7) and positive communication between students and academics, which appeared to give students a sense of support, encouragement, and inspiration. It also increased the academics' own experience of relatedness, as they felt valued and appreciated. In addition, two of these academics mentioned relatedness between students, which enabled them to learn from each other and work in collaborative ways all round:

They do learn from each other and they say, "Wow, have you seen that?' [...] so there's lots of that, so sometimes I [say], "Where did you get that from, can you teach me that?" [...] So they teach me as well, which is great. (P9)

The academics attributed this relatedness partly to the students' willingness to empathize and communicate, but also to their own interactive teaching styles which shifted away from what they perceived to be a more traditional didactic approach:

We try and promote a very much, an active learning environment. [...] One such thing would be that we try and get groups of students to discuss ideas in small groups, 
before maybe having it as an open forum. [...] I think that $[\ldots]$ [puts] more onus on the group to try and come up with ideas. (P7)

I think the way we can encourage that is being more flexible, talking to them, having a dialogue, $[\ldots]$ empowering them a little bit more. And you see that, their confidence just goes pffoosh. (P9)

All four of these academics emphasized the importance of being approachable and treating students as individuals in order to develop a sense of mutual affinity and personal connection. They acknowledged that this could require innovative thinking due to time and resource constraints, plus the approval of their managers:

We don't always have the capacity to [provide regular face-to-face guidance] for every single student. So it's finding the other ways to [...] give that personal element to the sharing and understanding. (P8)

I've the $[\ldots]$ normal schedule contact time [but] it's the freedom that I've been allowed by my bosses, to not spend all the time transferring knowledge but to be the mentor. (P10)

\section{Lack of fulfilment of the need for relatedness}

Six academics (P1-P6) felt that the majority of their students experienced a lack of relatedness. They made reference to low levels of rapport and meaningful communication, believing that this was largely because students tended to see academics not as mentors or coconstructors of learning but primarily as service providers who were obliged to comply with their consumer-like demands. These students appeared to engage with academics in a superficial and perfunctory way, and as such, did not internalize the values they were being taught or share the academics' enthusiasm for their subjects: 
There has been a general cultural change, perhaps a general shift in the way that academics are perceived. [...] We're sort of seen as people who can be the process rather than people who are experts. [...] I mean they've paid fees [and] [...] the way that I've seen it expressed is that, that students somehow feel that they have ownership over you in the way that you do something. (P4)

[As academics] we've always prided [...] ourselves [...] to try and be as approachable as possible. But I think unfortunately, what has superseded that is this new model, the student-as-consumer, [...] "I'm demanding that you help me". (P6)

The academics felt that this outlook had been fostered by HEI managers and marketing teams:

I think $[\ldots]$ as a university system, $[\ldots]$ we are sort of encouraging them really, to adopt this consumerist approach, rather like, $[\ldots]$ "Was the waiter in the restaurant nice to you, did they smile, did you have a good day?” (P1)

In addition, many students appeared unwilling to engage with each other on a scholarly level and the academics reported a general lack of intellectual discussion and 'academic buzz' (P4):

I think they get $[\ldots]$ lured into a false sense of security that [studying] can be done in isolation, and we try to explain to them that $[\ldots]$ collegiate working and things like that is important, and sharing of ideas. [...] But encouraging that, that's quite difficult sometimes. (P5)

The importance of relatedness among peers was highlighted in a study by Bunce, Bennett, and Jones (2019), which showed that the more that students identified with other students on their course, the more likely they were to take a deep as opposed to surface approach to 
learning.

All academics in this subtheme made reference to extensive numbers of ways in which they had tried to improve relatedness. Teaching methods included open-door policies, group activities, peer support systems, interactive online resources, and online discussion boards. They reported that students were often reluctant to make use of these opportunities, however. These academics also felt that their efforts were hindered by time and resource constraints, and by the way in which they were being 'micromanaged to a much greater degree' (P6) by their managers. They felt the lack of genuine, positive, reciprocal interaction to be detrimental on all sides, as it diminished the levels of empathy and trust necessary for proper collaborative or mentoring relationships. The academics were left feeling distanced and devalued, aware of undercurrents of tension between themselves, their students, and their managers:

I think it's moved much more... [...] there's a sort of element, [...] [as a student] you go in there and $[\ldots]$ instead of sort of trying to be with the lecturer you're against them. [...] [As a lecturer] you just think... Oh God, this is going to be quite difficult really. (P1)

I know staff that are concerned, about... to make mistakes, or to [...] be able to tell students off for being late, or [...] for talking in a class, because they're concerned that that's going to create complaint, or affect the NSS. (P5)

\section{General Discussion}

This research examined academics' perceptions of the extent to which their students appeared to experience fulfilment of their needs for competence, autonomy, and relatedness in a marketized HE context. It also examined academics' perceptions of whether their own psychological needs were fulfilled, and the ways in which this influenced their teaching. The 
analysis revealed that six out of 10 academics (P1-P6) regarded the majority of their students as having relatively low competence, autonomy, and relatedness, which resulted in lowquality extrinsic motivation (external or introjected regulation). Many of these students seemed to adopt consumer-like attitudes and behaviours, focusing primarily on the extrinsic goal of gaining a degree in order to get graduate employment. These academics also felt that their own psychological needs were being undermined, which inhibited their endeavours to teach in ways that enhanced student motivation. In contrast, three academics (P8-P10) regarded the majority of their students as experiencing relatively high fulfilment of their three psychological needs, which resulted in intrinsic or high-quality extrinsic motivation (identification or integrated regulation). These students did not seem to identify as consumers, or had overcome their initial consumer orientations and developed strong enthusiasm for their subjects. This supported the academics' own feelings of competence, autonomy, and relatedness, and enabled them to use teaching styles that seemed to motivate both their students and themselves. One academic (P7) regarded the majority of his students as experiencing high levels of relatedness but relatively low levels of competence and autonomy. These students appeared to have 'a real mix' of motivations, and although only 'a handful' displayed explicit consumer-like attitudes and behaviours, many seemed to expect more 'value for money' due to high tuition fees (P7).

On a descriptive level, these findings support and extend previous research by showing with greater depth and consistency how defining students as consumers of HE also appears to diminish their quality of motivation. When students were seen by academics to identify as consumers, their attitudes and behaviours towards learning (e.g., passivity, disengagement, low effort, surface level approaches, focus on instrumental end goals) reflected those reported in other studies (e.g., Bunce et al., 2017; Bunce \& Bennett, 2019; Haywood et al., 2011; Jabbar et al., 2018; Nixon et al., 2011; Rolfe, 2002; Tomlinson, 2014, 2017; Wong \& Chiu, 
2019). On an interpretative level, analyzing the data using SDT gave a potential explanation for why this apparent decline in student motivation occurs: when students are educated in a marketized HE context, their consumer-like attitudes and behaviours contribute to a climate that impedes fulfilment of both their own and their academics' basic psychological needs. In turn, this inhibits students' intrinsic motivation for learning and academics' motivation for teaching.

These findings are novel because they highlight the importance of taking into account the influence of external contexts that operate beyond the classroom when applying SDT to education. Although a number of publications have acknowledged that educators' teaching styles may be affected by social and institutional pressures (e.g., Deci et al., 1991; Niemiec \& Ryan, 2009; Martinek, 2019; Pelletier et al., 2002), these factors have been largely overlooked in empirical studies. The current study revealed that, although all academics interviewed reported how they had tried to teach in ways that fostered students' intrinsic motivation, six felt that they were being restrained by a pervasive consumerist discourse that had determined both their students' and their managers' expectations of how their teaching should be conducted. This indicates that the effects of external contexts on the motivation of educators, as well as students, is a pertinent area for further exploration. Such contexts could operate on a system level (e.g., curricula demands, educational policy reforms), an institutional level (e.g., structural and material resources, leadership styles), and an individual level (e.g., personal time constraints, students' behaviour) (Martinek, 2019).

The findings also provide novel insight into the detrimental impact of defining students as consumers. By applying SDT, this study drew on over three decades' worth of empirical evidence showing that a lack of competence, autonomy, and relatedness leads to extrinsic motivation and low achievement, satisfaction, engagement, persistence, creativity, wellbeing, and personal growth (Ryan \& Deci, 2000, 2002). In addition, SDT allows researchers to 
'specify the contextual conditions that will facilitate motivation, performance, and development' (Deci et al., 1991, p. 327). Whereas previous research on the marketized HE context has highlighted a broad range of complex and sometimes conflicting attitudes and behaviours held by student 'consumers', the current study presents a clearer, more welldefined model for potential interventions: HEIs could place greater emphasis on creating an environment that supports the basic psychological needs of both students and academics to facilitate intrinsic motivation for learning and teaching respectively.

In terms of policy and practical implications, this study suggests that policymakers should avoid defining students as consumers, and instead endorse student identities that encourage them to value learning for its own sake and make important contributions to the knowledge economy as opposed to the financial one. For example, redefining students as co-producers or 'partners' (Tomlinson, 2014, p. 8) would emphasize the complex and experiential nature of learning at HEIs, as opposed to the service provider model that positions students as feepaying customers. HEIs would have a critical role to play in promoting and sustaining such identities, which would require collaboration between staff at all levels. A unanimous approach from senior management, middle management, academics, and professional service staff could ensure consistency in shaping potential and current students' expectations of their HEI experience, and specifically the nature of learning. Emphasis on partnership and learning rigour, alongside minimization of consumer discourse, should be applied at all stages of student recruitment, induction, teaching, and assessment processes, and communicated clearly in official documents including student charters, student contracts, learning agreements, and degree course guides. It could also be reinforced during teaching courses for academics, especially those in early career positions. Marketing materials aimed at demonstrating the quality of facilities and resources of HEIs, such as state-of-the-art lecture theatres and innovative libraries, should be balanced with content that describes the nature of 
student engagement required to gain the full value of the educational experience. The current study also demonstrates that it is essential for HEIs to support academics in creating and maintaining high-quality learning environments, and developing and implementing optimal teaching styles that place student learning above more superficial forms of student satisfaction.

\section{Limitations}

This was an interview study providing qualitative analysis of 10 academics' experiences of teaching students at five post-1992 HEIs, so the sample was not intended to represent the full variety of different HEIs and degree subjects in England. Further research could extend these findings, for example by using surveys to examine the views of a more representative sample of academics on the impact of a marketized HE context on their students' and their own motivation for learning and teaching, using SDT.

\section{Conclusions}

According to SDT, students who experience fulfilment of their needs for competence, autonomy, and relatedness have higher-quality motivation and are likely to be more active and engaged, put more effort into learning, use better learning approaches, and achieve higher levels of academic performance (Deci et al., 1991; Niemiec \& Ryan, 2009; Ryan \& Deci, 2000, 2002). However, the marketization of HE in England, and in other countries where students are defined as consumers of their education, is potentially undermining both students' and academics' motivation by pushing them to focus on target-driven extrinsic goals. Academics can play a pivotal role in shaping students' HE experiences, but in the current study, the majority of participants felt demotivated and disempowered by an ongoing ideological transformation. They felt that this change was inhibiting inventive teaching styles and genuine student-educator interaction, both through top-down pressure from managers and 
bottom-up pressure from student 'consumers'. Three academics were more optimistic and noted that, when they were given sufficient control over teaching by their managers, they were able to foster students' intrinsic motivation for learning. It is clear, however, that this is being seen as increasingly difficult in the contemporary climate in which students are encouraged to seek value for money above other forms of educational value. 


\section{References}

Braun, V., \& Clarke, V. (2006). Using thematic analysis in psychology. Qualitative Research in Psychology, 3(2), 77-101. https://doi.org/10.1191/1478088706qp063oa

Braun, V. \& Clarke, V. (2012). Thematic analysis. In H. Cooper, P. M. Camic, D. L. Long, A. T. Panter, D. Rindskopf, \& K. J. Sher (Eds.), APA handbook of research methods in psychology (Vol. 2, pp. 57-71). Washington, DC: American Psychological Association.

Bunce, L., Baird, A., \& Jones, S. E. (2017). The student-as-consumer approach in higher education and its effects on academic performance. Studies in Higher Education, 42, 1958-1978. https://doi.org/10.1080/03075079.2015.1127908

Bunce, L., \& Bennett, M. (2019). A degree of studying? Approaches to learning and academic performance among student 'consumers'. Active Learning in Higher Education. https://doi.org/10.1177/1469787419860204

Bunce, L., Bennett, M., \& Jones, S. (2019). The impact of complaining on approaches to learning and academic performance in undergraduates: A social identity approach. Manuscript submitted for publication.

Chapleo, C. (2010). What defines "successful" university brands? International Journal of Public Sector Management, 23, 169-183. https://doi.org/10.1108/09513551011022519

Deci, E. L., Vallerand, R. J., Pelletier, L. G., \& Ryan, R. M. (1991). Motivation and education: The self-determination perspective. Educational Psychologist, 26, 325346. https://doi.org/10.1080/00461520.1991.9653137 
Department for Business, Innovation, and Skills. (2011, June). Higher education: Students at the heart of the system [White paper $\mathrm{Cm} 8122$ ]. Retrieved from https://assets.publishing.service.gov.uk/government/uploads/system/uploads/attachme nt_data/file/31384/11-944-higher-education-students-at-heart-of-system.pdf

Department for Business, Innovation, and Skills. (2016, May 19). Higher Education and Research Bill: Factsheet [Policy paper BIS/16/285]. Retrieved from https://www.gov.uk/government/publications/higher-education-and-research-billsummary-factsheet

Entwistle, N., McCune, V., \& Walker, P. (2001). Conceptions, styles and approaches within higher education: Analytic abstractions and everyday experience. In R. J. Sternberg \& L.-F. Zhang (Eds.), Perspectives on thinking, learning, and cognitive styles (pp. 103136). Abingdon, UK: Routledge.

Fereday, J., \& Muir-Cochrane, E. (2006). Demonstrating rigor using thematic analysis: A hybrid approach of inductive and deductive coding and theme development. International Journal of Qualitative Methods, 5(1), 80-92. https://doi.org/10.1177/160940690600500107

Galletta, A. (2013). Mastering the semi-structured interview and beyond: From research design to analysis and publication. New York, NY: New York University Press.

Gokcen, N. (2014, December). New voices: The rise of student consumerism. The Psychologist, 27, 940-941. Retrieved from https://thepsychologist.bps.org.uk/system/files/1214gokc.pdf

Grove, J. (2017, February 16). Times Higher Education (THE) Teaching Survey 2017: Results and analysis. Retrieved from 
https://www.timeshighereducation.com/features/the-teaching-survey-2017-resultsand-analysis/

Haywood, H., Jenkins, R., \& Molesworth, M. (2011). A degree will make all your dreams come true: Higher education as the management of consumer desires. In M. Molesworth, E. Nixon, \& R. Scullion (Eds.), The marketization of higher education and the student as consumer (pp. 183-195). Abingdon, UK: Routledge.

Jabbar, A., Analoui, B., Kong, K., \& Mirza, M. (2018). Consumerisation in UK higher education business schools: Higher fees, greater stress and debatable outcomes. Higher Education, 76(1), 85-100. https://doi.org/10.1007/s10734-0170196-Z

Komljenovic, J., Ashwin, P., McArthur, J., \& Rosewell, K. (2018). To be or not to be consumers: The imperfect alignment of English higher education marketization policy and the narratives of first year university students. Paper presented at the Centre for Global Higher Education 2018 Annual Conference: The new geopolitics of higher education, London, England. Retrieved from https://www.researchcghe.org/perch/resources/uk-sa-cg-paper-22.3.18.pdf

Martinek, D. (2019). The consequences of job-related pressure for self-determined teaching. Social Psychology of Education, 22(1), 133-148. https://doi.org/10.1007/s11218-018-9446-x

Marton, F., \& Säljö, R. (1976). On qualitative differences in learning: I-Outcome and process. British Journal of Educational Psychology, 46(1), 4-11. https://doi.org/10.1111/j.2044-8279.1976.tb02980.x 
Molesworth, M., Nixon, E., \& Scullion, R. (2009). Having, being and higher education: The marketisation of the university and the transformation of the student into consumer. Teaching in Higher Education, 14, 277-287. https://doi.org/10.1080/13562510902898841

Moran, H., \& Powell, J. (2018). Running a tight ship: Can universities plot a course through rough seas? Retrieved from https://uploads.guim.co.uk/2018/01/30/Guardian_HSBC_UUK_Research_full_report -V4.pdf

Morrish, L. (2019, May). Pressure vessels: The epidemic of poor mental health among higher education staff (HEPI Occasional Paper 20). https://www.hepi.ac.uk/wpcontent/uploads/2019/05/HEPI-Pressure-Vessels-Occasional-Paper-20.pdf

Naidoo, R., Shankar, A., \& Veer, E. (2011). The consumerist turn in higher education: Policy aspirations and outcomes. Journal of Marketing Management, 27, 1142-1162. https://doi.org/10.1080/0267257X.2011.609135

Niemiec, C. P., \& Ryan, R. M. (2009). Autonomy, competence, and relatedness in the classroom: Applying self-determination theory to educational practice. School Field, 7, 133-144. https://doi.org/10.1177/1477878509104318

Nixon, E., Scullion, R., \& Molesworth, M. (2011). How choice in higher education can create conservative learners. In M. Molesworth, E. Nixon, \& R. Scullion (Eds.), The marketization of higher education and the student as consumer (pp. 196-208). Abingdon, UK: Routledge. 
Nowell, L. S., Norris, J. M., White, D. E., \& Moules, N. J. (2017). Thematic analysis: Striving to meet the trustworthiness criteria. International Journal of Qualitative Methods, 16(1), 1-13. https://doi.org/10.1177/1609406917733847

Patton, M. Q. (1990). Qualitative evaluation and research methods. Newbury Park, CA: Sage.

Pelletier, L. G., Séguin-Lévesque, C., \& Legault, L. (2002). Pressure from above and pressure from below as determinants of teachers' motivation and teaching behaviors. Journal of Educational Psychology, 94(1), 186-196. https://doi.org/10.1037/0022-0663.94.1.186

Rolfe, H. (2002). Students' demands and expectations in an age of reduced financial support: The perspectives of lecturers in four English universities. Journal of Higher Education Policy and Management, 24, 171-182. https://doi.org/10.1080/1360080022000013491

Ryan, R. M., \& Deci, E. L. (2000). Intrinsic and extrinsic motivations: Classic definitions and new directions. Contemporary Educational Psychology, 25(1), 54-67. https://doi.org/10.1006/ceps.1999.1020

Ryan, R. M., \& Deci, E. L. (2002). Overview of self-determination theory: An organismic dialectical perspective. In E. L. Deci, \& R. M. Ryan (Eds.), Handbook of selfdetermination research (pp. 3-33). Rochester, NY: University of Rochester Press.

Tomlinson, M. (2014, April 4). Exploring the impacts of policy changes on student approaches and attitudes to learning in contemporary higher education: Implications for student learning engagement. Retrieved from 
https://www.heacademy.ac.uk/system/files/resources/exploring_the_impact_of_policy _changes_student_experience.pdf/

Tomlinson, M. (2017). Student perceptions of themselves as 'consumers' of higher education. British Journal of Sociology of Education, 38, 450-467. https://doi.org/10.1080/01425692.2015.1113856

Wengraf, T. (2001). Qualitative research interviewing: Biographic narrative and semistructured methods. London, UK: Sage.

Williams, J. (2011). Constructing consumption: What media representations reveal about today's students. In M. Molesworth, E. Nixon, \& R. Scullion (Eds.), The marketization of higher education and the student as consumer (pp. 170-182). Abingdon, UK: Routledge.

Wolf, Z. R. (2003). Exploring the audit trail for qualitative investigations. Nurse Educator, 28, 175-178. https://doi.org/10.1097/00006223-200307000-00008

Wong, B., \& Chiu, Y. L. T. (2019). Let me entertain you: The ambivalent role of university lecturers as educators and performers. Educational Review, 71, 1-16. https://doi.org/10.1080/00131911.2017.1363718 